Supporting Information for

\title{
Experimental and Computational Study of Natural gas Pyrolysis in a Pilot-scale Cracker
}

Byeongjin Baek*, Balamurali Nair, Istvan Lengyel, Lei Chen, Sreekanth Pannala, Retheesh VM, and David West

SABIC Global Corporate Research, 1600 Industrial Blvd, Sugar Land TX, 77478, USA

Corresponding author: Byeongjin Baek (bbaek@sabic.com) 

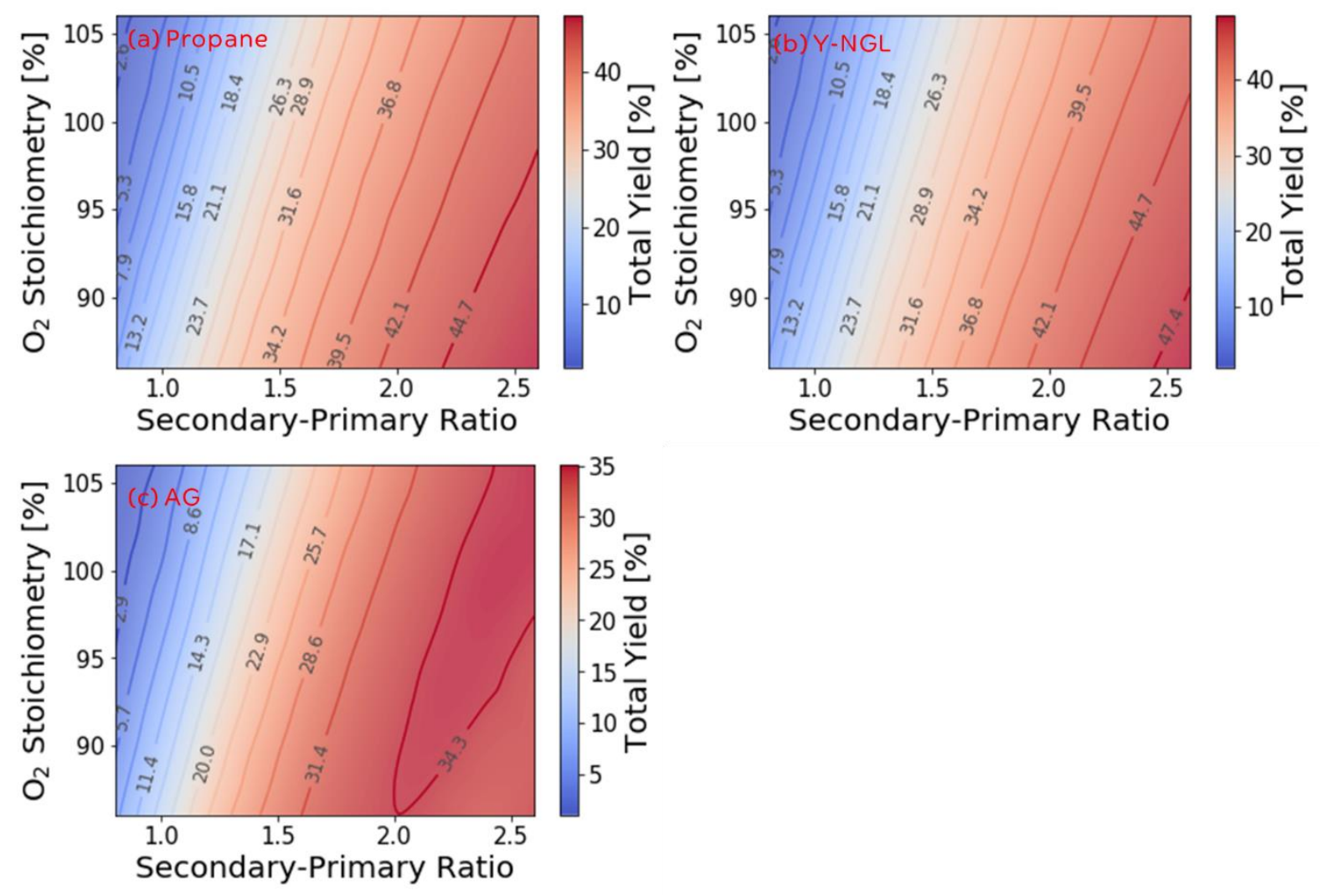

Figure S1. Predicted total C2 carbon yield from kinetic models. All simulations were performed under adiabatic conditions: (a) propane, (b) Y-NGL, and (c) associated gas (AG). Fuel gas was natural gas. Composition of natural gas, propane, surrogate $\mathrm{Y}-\mathrm{NGL}$, and surrogate-associated gas are summarized in Table 1 (see manuscript).

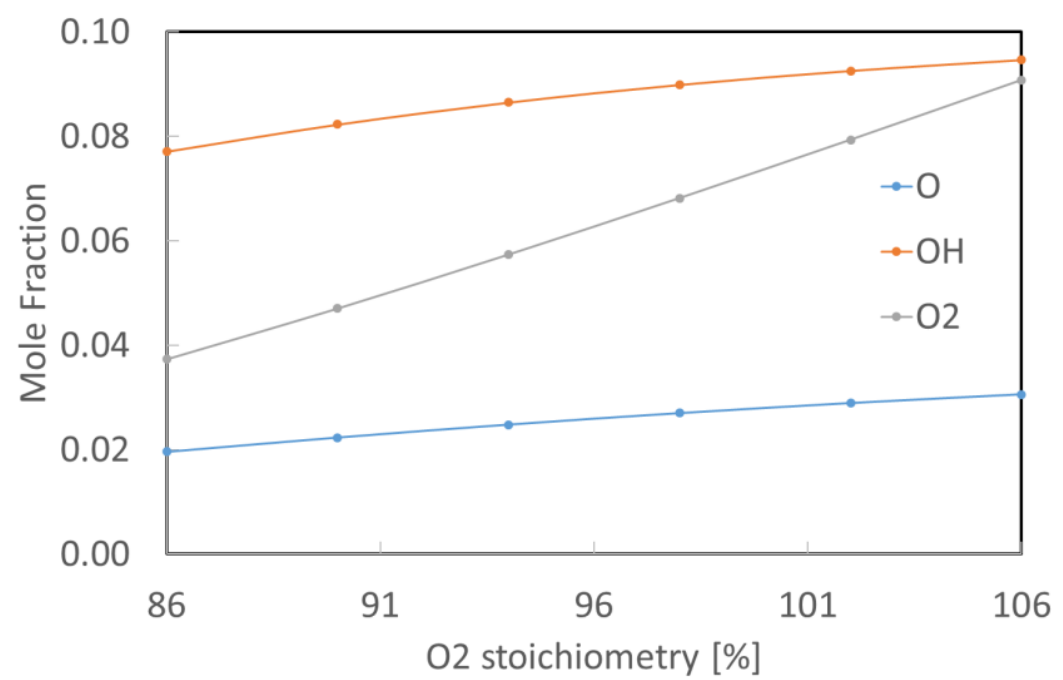

Figure S2. Concentrations of $\mathrm{OH}, \mathrm{O}$ and $\mathrm{O}_{2}$ with respect to $\mathrm{O}_{2}$ stoichiometry. The concentrations were wet basis and collected from the combustor effluent. 


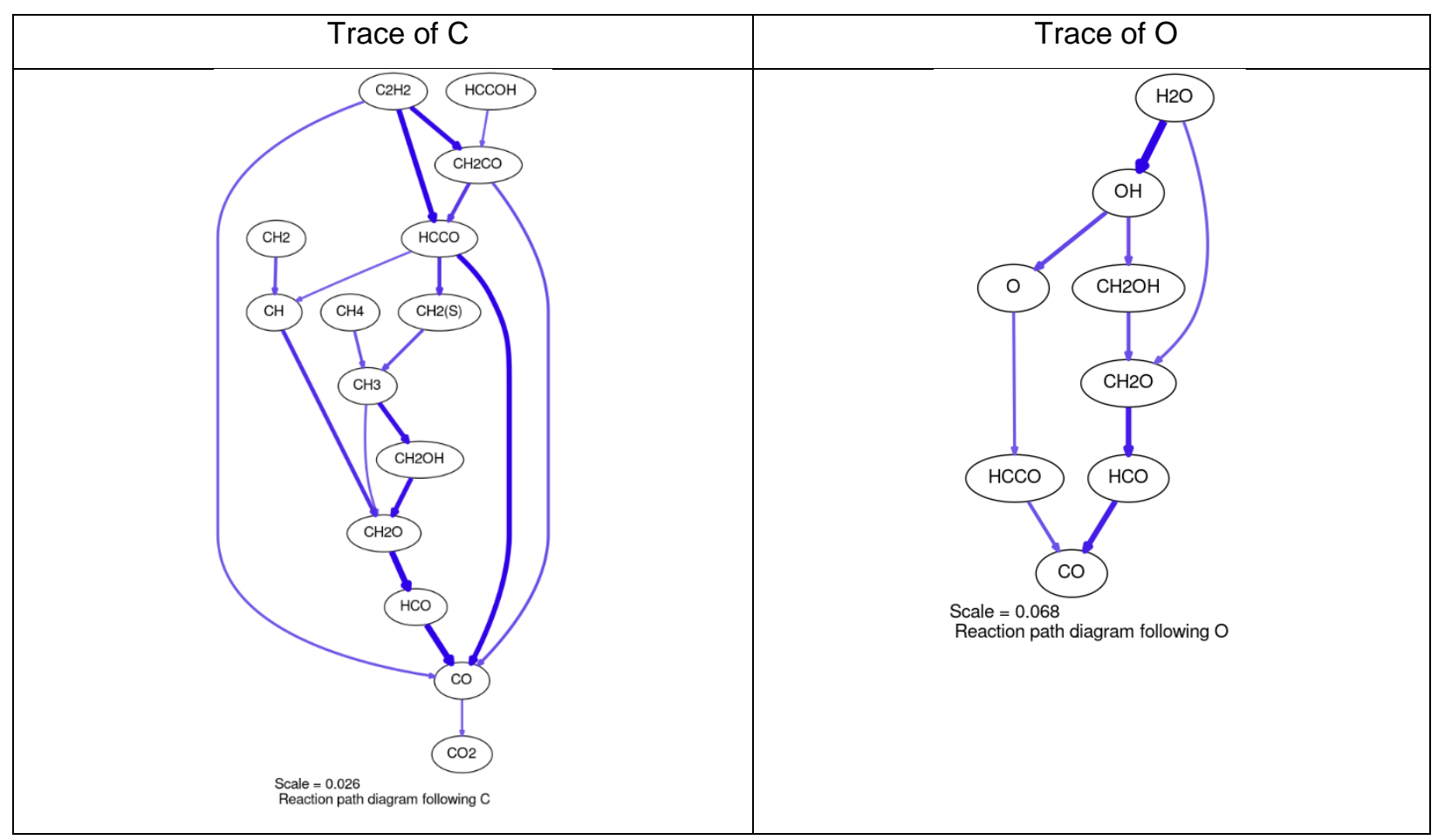

Figure S3. Reaction path analysis at $\mathrm{O}_{2}$ Stoichiometry of $100 \%$ and S/P ratio of 1.0. Data was sampled at the distance of $0.00254 \mathrm{~m}$ in the pyrolysis reactor.

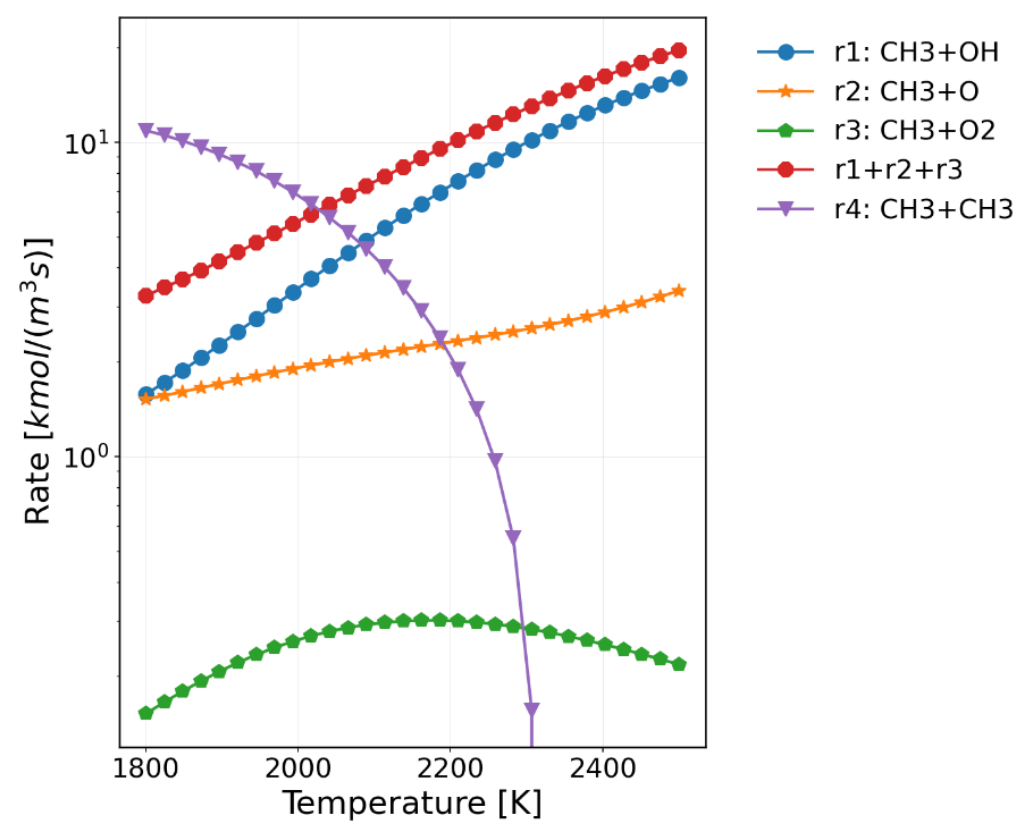

Figure S4. Rate of reactions as a function of temperature; (r1) rate of $\mathrm{CH}_{3}$. recombination with $\mathrm{OH} \cdot$, (r2) rate of $\mathrm{CH}_{3}$. recombination with $\mathrm{O} \cdot ;(\mathrm{r} 3)$ rate of $\mathrm{CH}_{3}$ recombination with $\mathrm{O}_{2}$; and (r4) rate of $\mathrm{CH}_{3}$ radical recombination. Reaction conditions were chosen from the case with SP of 1.75 and OS of 86. 


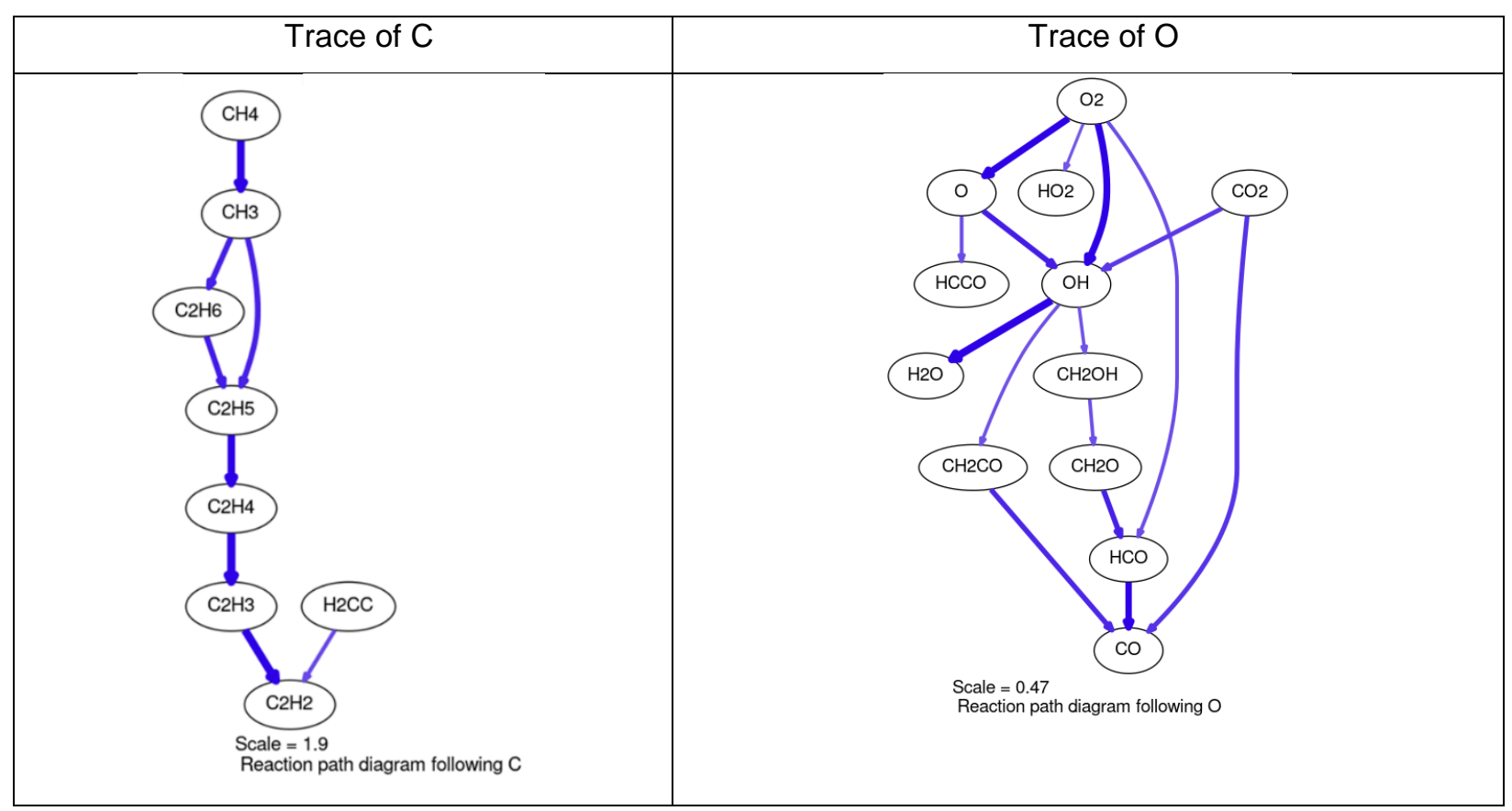

Figure S5. Reaction path analysis at the $\mathrm{O}_{2}$ Stoichiometry of $102 \%$ and S/P ratio of 2.4. Data was sampled at the distance of $0.00254 \mathrm{~m}$ in the pyrolysis reactor.

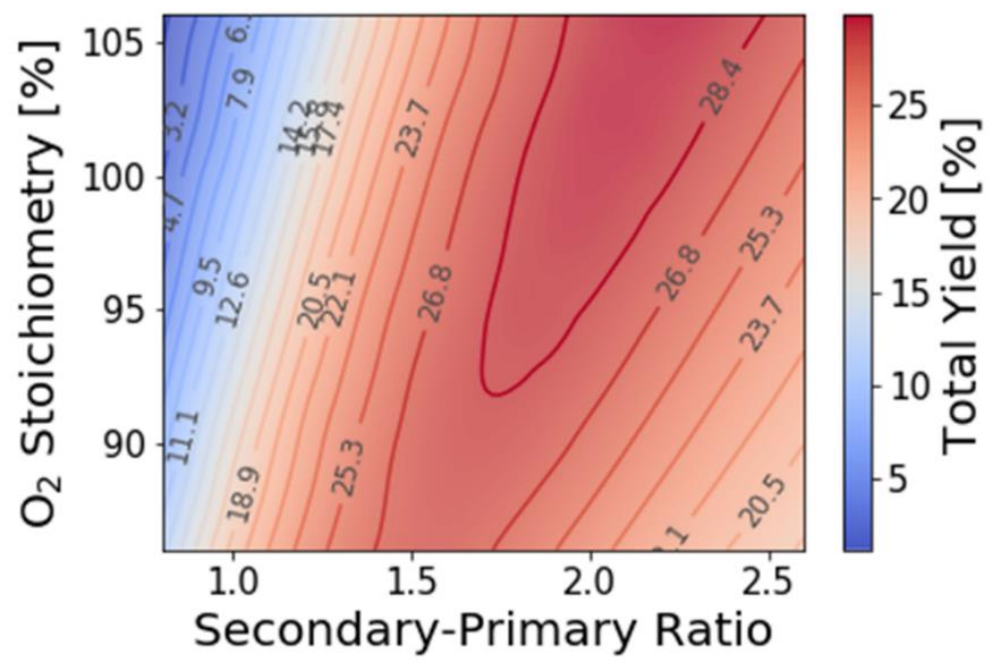

Figure S6. Maximum carbon-based total C2 olefin yields observed in the pilot scaled reactor with heat loss observed in the experiment. Estimated heat loss is $21 \%$ with respect to low heating value of natural gas. 
Table S1. Comparisons between simulations and experimental data. Data were measured / collected at the mean residence time of $0.5 \mathrm{~ms}$. Heat loss is a percent of heat loss with respect to low heating value (LHV) of fuel gas (natural gas).

\begin{tabular}{|c|c|c|c|c|c|c|c|c|}
\hline & & Experimer & & Model & Experimer & Model & Experimen & Model \\
\hline \multicolumn{2}{|c|}{ Fuel gas } & \multicolumn{3}{|c|}{ NG } & \multicolumn{2}{|c|}{$N G$} & \multicolumn{2}{|c|}{$N G$} \\
\hline \multicolumn{2}{|c|}{ Crack gas } & \multicolumn{3}{|c|}{$N G$} & \multicolumn{2}{|c|}{$N G$} & \multicolumn{2}{|c|}{$N G$} \\
\hline \multicolumn{2}{|c|}{$\dot{m}_{\text {fuel }}[\mathrm{lb} / \mathrm{h}]$} & \multicolumn{3}{|c|}{865} & \multicolumn{2}{|c|}{672} & \multicolumn{2}{|c|}{575} \\
\hline \multicolumn{2}{|c|}{$\dot{m}_{\text {crack }}[\mathrm{lb} / \mathrm{h}]$} & \multicolumn{3}{|c|}{606} & \multicolumn{2}{|c|}{606} & \multicolumn{2}{|c|}{606} \\
\hline \multicolumn{2}{|c|}{ Firing rate $[\mathrm{MMBTU} / \mathrm{h}]$} & \multicolumn{3}{|c|}{17.6} & \multicolumn{2}{|c|}{13.6} & \multicolumn{2}{|c|}{11.6} \\
\hline \multicolumn{2}{|c|}{$\mathrm{O}_{2}$ stoichiometry [\%] } & \multicolumn{3}{|c|}{86.7} & \multicolumn{2}{|c|}{86.9} & \multicolumn{2}{|c|}{86.6} \\
\hline \multicolumn{2}{|c|}{$\mathrm{S} / \mathrm{P}$ ratio } & \multicolumn{3}{|c|}{0.7} & \multicolumn{2}{|c|}{0.9} & \multicolumn{2}{|c|}{1.1} \\
\hline \multicolumn{2}{|c|}{ Heat Loss [\%] } & \multicolumn{3}{|c|}{16.4} & \multicolumn{2}{|c|}{17.9} & \multicolumn{2}{|c|}{19.2} \\
\hline \multirow{7}{*}{$\begin{array}{c}\text { Exit } \\
\text { Mole [\%] }\end{array}$} & $\mathrm{H}_{2}$ & 42.3 & & 50.3 & 40.9 & 51.0 & 39.9 & 47.8 \\
\hline & $\mathrm{CO}_{2}$ & 16.0 & & 7.1 & 14.8 & 7.7 & 13.6 & 10.8 \\
\hline & $\mathrm{CH}_{4}$ & 6.6 & & 0.0 & 10.5 & 1.4 & 13.7 & 5.4 \\
\hline & $\mathrm{C}_{2} \mathrm{H}_{4}$ & 0.2 & & 0.0 & 0.4 & 0.0 & 0.5 & 0.1 \\
\hline & $\mathrm{C}_{2} \mathrm{H}_{2}$ & 2.9 & & 0.0 & 3.6 & 2.8 & 3.7 & 6.5 \\
\hline & $\mathrm{CO}$ & 30.4 & & 40.8 & 28.2 & 36.0 & 27.1 & 27.7 \\
\hline & $\mathrm{O}_{2}$ & 1.0 & & 0.0 & 1.0 & 0.0 & 0.8 & 0.0 \\
\hline Yield [\%] & Overall & 10.7 & & 0.5 & 12.9 & 10.9 & 13.2 & 22.3 \\
\hline
\end{tabular}
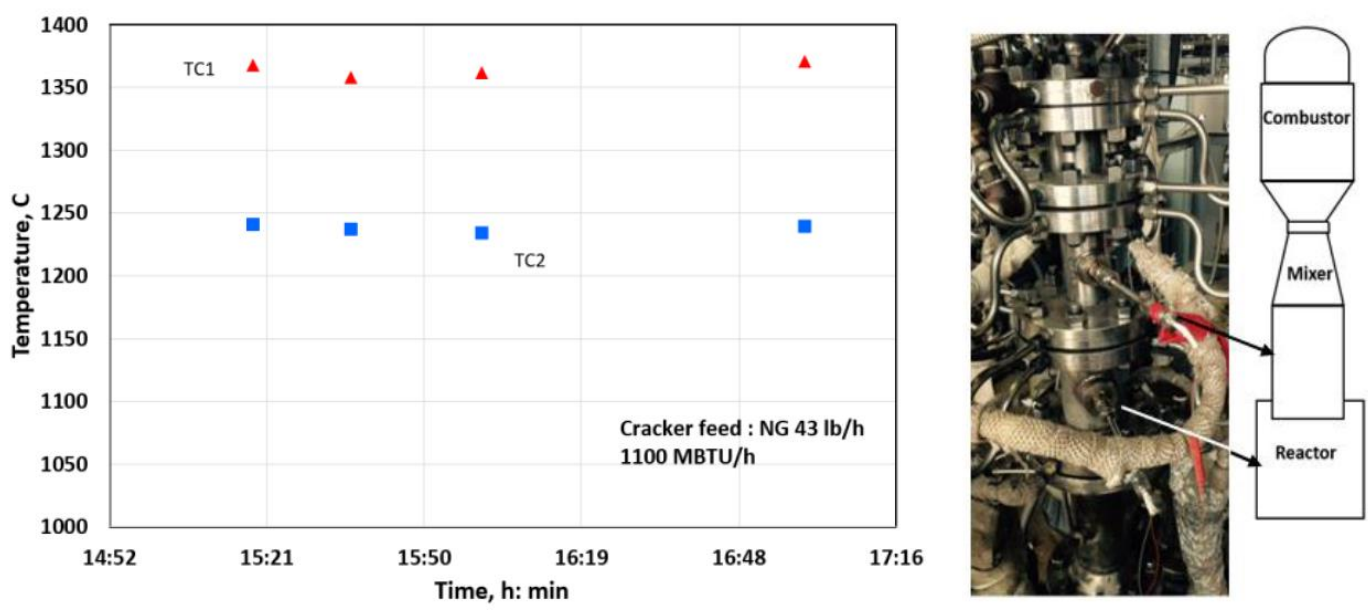

Figure S7. Temperature measurement from the previous experiment at which the reactor size was approximately 20 times smaller than the pilot-scaled reactor. Two thermocouples (TC1 and TC2) were installed in the scale-down reactor. TC1 was located 3.5" downstream of the throat, whereas TC2 was located at 10.5 " from the throat. The temperature near the entrance of the reactor was around $1370{ }^{\circ} \mathrm{C}$ for typical operation with an S/P of around 0.8 . 


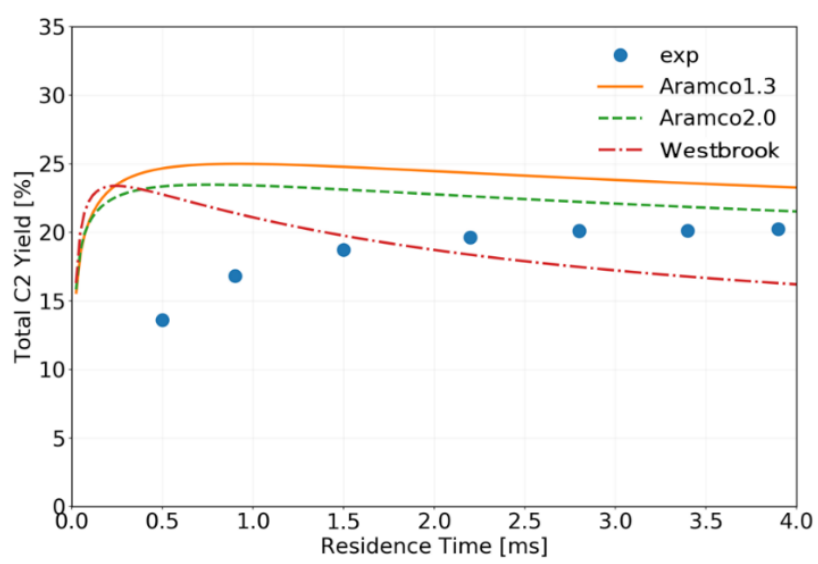

Figure S8. Comparison of experimental data with the kinetic models. Detailed mechanisms used in this benchmark study are Aramco1.3, Aramco2.0, and Westbrook. ${ }^{1-8}$ The Aramco1.3 is the one used in the main text. The number of reactions and species are summarized in below table.

\begin{tabular}{|c|c|c|c|}
\hline & \# species & \# steps & The highest C\# \\
\hline Aramco1.3 & 253 & 1542 & C4 \\
\hline Aramco2.0 & 493 & 2716 & C6 \\
\hline Westbrook & 1389 & 10481 & C12 \\
\hline
\end{tabular}

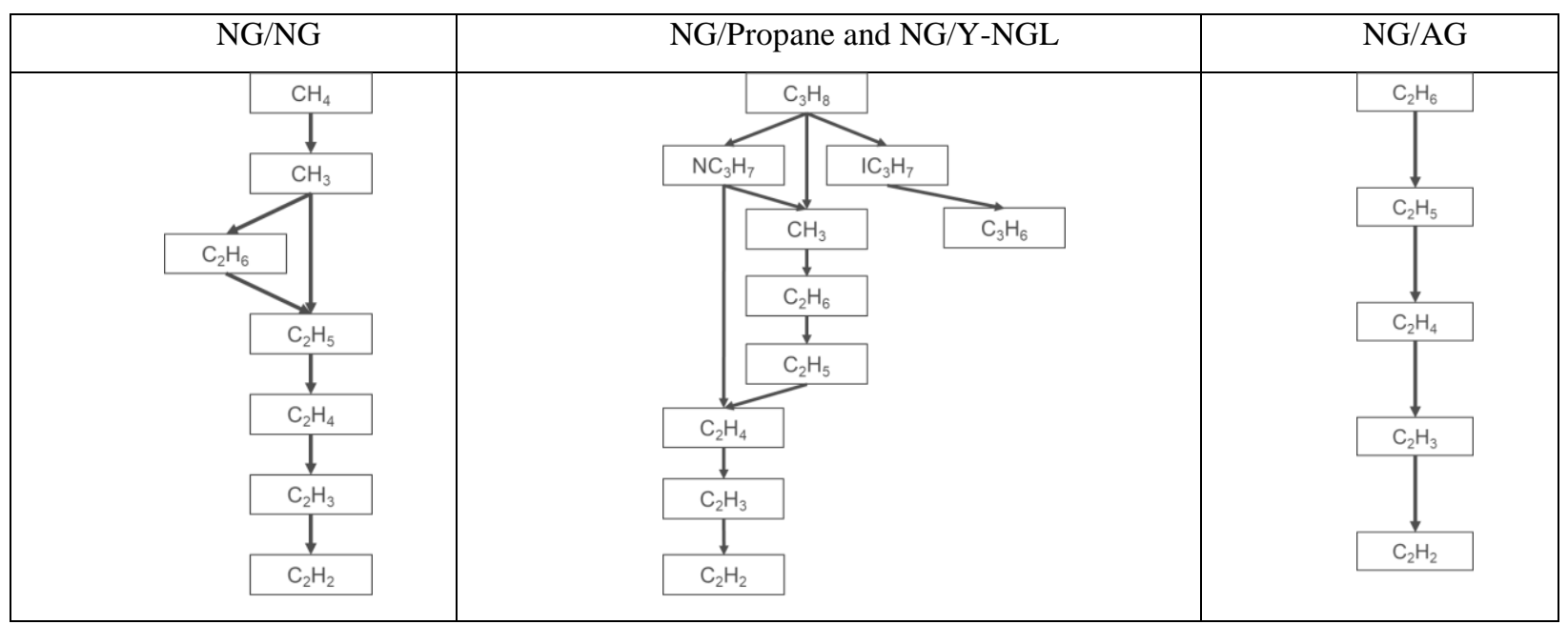

Figure S9. Simplified reaction pathway analysis for NG/NG, NG/Propane, NG/Y-NGL, and NG/AG. The most dominant reaction pathways were only included - other steps occurred in parallel (at relatively slow rates) were removed for clarity. All these analysis were carried out at the residence time below 0.05 ms (i.e. near the entrance of the pyrolysis reactor). 


\section{References}

(1) Metcalfe, W. K.; Burke, S. M.; Ahmed, S. S.; Curran, H. J. A Hierarchical and Comparative Kinetic Modeling Study of C1-C2 Hydrocarbon and Oxygenated Fuels. Int. J. Chem. Kinet. 2013, 45 (10), 638-675.

(2) Li, Y.; Zhou, C.-W.; Somers, K. P.; Zhang, K.; Curran, H. J. The Oxidation of 2-Butene: A High Pressure Ignition Delay, Kinetic Modeling Study and Reactivity Comparison with Isobutene and 1Butene. Proc. Combust. Inst. 2017, 36 (1), 403-411.

(3) Zhou, C.-W.; Li, Y.; O'Connor, E.; Somers, K. P.; Thion, S.; Keesee, C.; Mathieu, O.; Petersen, E. L.; DeVerter, T. A.; Oehlschlaeger, M. A.; Kukkadapu, G.; Sung, C.-J.; Alrefae, M.; Khaled, F.; Farooq, A.; Dirrenberger, P.; Glaude, P.-A.; Battin-Leclerc, F.; Santner, J.; Ju, Y.; Held, T.; Haas, F. M.; Dryer, F. L.; Curran, H. J. A Comprehensive Experimental and Modeling Study of Isobutene Oxidation. Combust. Flame 2016, 167, 353-379.

(4) Burke, U.; Metcalfe, W. K.; Burke, S. M.; Heufer, K. A.; Dagaut, P.; Curran, H. J. A Detailed Chemical Kinetic Modeling, Ignition Delay Time and Jet-Stirred Reactor Study of Methanol Oxidation. Combust. Flame 2016, 165, 125-136.

(5) Burke, S. M.; Burke, U.; Mc Donagh, R.; Mathieu, O.; Osorio, I.; Keesee, C.; Morones, A.; Petersen, E. L.; Wang, W.; DeVerter, T. A.; Oehlschlaeger, M. A.; Rhodes, B.; Hanson, R. K.; Davidson, D. F.; Weber, B. W.; Sung, C.-J.; Santner, J.; Ju, Y.; Haas, F. M.; Haas, F. M.; Dryer, F. L.; Volkov, E. N.; Nilsson, E. J.K.; Konnov, A. A.; Alrefae, M.; Khaled, F.; Farooq, A.; Dirrenberger, P.; Glaude, P.A.; Battin-Leclerc, F.; Curran, H. J. An Experimental and Modeling Study of Propene Oxidation. Part 2: Ignition Delay Time and Flame Speed Measurements. Combust. Flame 2015, 162 (2), 296-314.

(6) Burke, S. M.; Metcalfe, W.; Herbinet, O.; Battin-Leclerc, F.; Haas, F. M.; Santner, J.; Dryer, F. L.; Curran, H. J. An Experimental and Modeling Study of Propene Oxidation. Part 1: Speciation Measurements in Jet-Stirred and Flow Reactors. Combust. Flame 2014, 161 (11), 2765-2784.

(7) Kéromnès, A.; Metcalfe, W. K.; Heufer, K. A.; Donohoe, N.; Das, A. K.; Sung, C.-J.; Herzler, J.; Naumann, C.; Griebel, P.; Mathieu, O.; Krejci, M. C.; Petersen, E. L.; Pitz, W. J.; Curran, H. J. An Experimental and Detailed Chemical Kinetic Modeling Study of Hydrogen and Syngas Mixture Oxidation at Elevated Pressures. Combust. Flame 2013, 160 (6), 995-1011.

(8) Westbrook, C. K.; Pitz, W. J.; Herbinet, O.; Curran, H. J.; Silke, E. J. A Comprehensive Detailed Chemical Kinetic Reaction Mechanism for Combustion of N-Alkane Hydrocarbons from N-Octane to N-Hexadecane. Combust. Flame 2009, 156 (1), 181-199. 